\title{
"Casa tomada" o la Auto-significación del Relato
}

\author{
El señor del oráculo, el de Delfos, \\ ni habla ni oculta. Significa. \\ Heráclito, Fr. 93.
}

Una pareja de hermanos vivía retirada del mundo, partiendo su tiempo entre el ocio y los quehaceres domésticos. Una noche, ruidos extraños en los trasfondos de la casa les hacen huir a la parte delantera. Ahí tratan de reanudar con sus costumbres, hasta ser sorprendidos por una nueva alerta que acaba echándoles a la calle.

El argumento de "Casa tomada" sume al lector menos prevenido en un abismo de perplejidades que no pudo sortear una crítica empeñada en darle un contenido inteligible. Publicado una primera vez con el asentimiento de Borges, el relato tomó buen sitio en la Antología de la literatura fantástica. ${ }^{1}$ Tal augurio, lejos de guiar los pasos de los comentaristas hacia la búsqueda de sus arcanos, dio cuerpo a la intuición poco comprometedora de que el texto era la transcripción literaria de una pesadilla. A partir de esta escapatoria empiezan las discrepancias. Unos optaron por atenerse al simbolismo de un cuento finalmente recogido por el mismo Cortázar en su Bestiario, otros creyeron oportuno

1 Cabe señalar a la curiosidad del lector el propio testimonio de Borges: "Yo me encontré con Cortázar en París, en casa de Néstor Ibarra. El me dijo: "¿Usted selacuerdaíde lo que nos pasó aquella tarde en la diagonal Norte?" "No", le dije yo. Entonces él me dijo: "Yo le llevé a usted un manuscrito. Usted me dijo que volviera al cabo de una semana, y que usted me diría lo que pensaba del manuscrito". Yo dirigia entonces una revista, los Anales de Buenos Aires (una revista ahora injustamente olvidada), que pertenecía a la señora Sara de Ortiz Basualdo, y él me llevó un cuento, "Casa tomada"; al cabo de una semana volvió. Me pidió mi opinión, y yo le dije: "En lugar de darle mi opinión, voy a decirle dos cosas: una, que el cuento está en la imprenta, y dentro de unos días tendremos las pruebas; y otra, que ya le he encargado las ilustraciones a mi hermana Norah". Pero en esa ocasión, en París, Cortázar me dijo: "Lo que yo quería recordarle también es que ése fue el primer texto que yo publiqué en mi patria cuando nadie me conocía". "Y yo me sentí muy orgulloso de haber sido el primero que publicó un texto de Julio Cortázar". (Véase Fernando Sorrentino, Siete conversaciones con Jorge Luis Borges, (Buenos Aires: Casa Pardo SA, 1973), pp. 52-53. Con todo, la inserción del cuento en la Antologia resulta bastante tardía. Hemos consultado la cuarta edición (tercera en la colección Piragua: Buenos Aires: Editorial Sudamericana: 1971, p. 150-155), de la cual sacamos las citas incluídas en el presente trabajo. 
prestarle sin más reparos una dimensión socio-histórica a la agorafobia de los personajes. Así, donde Emma Susana Speratti Piñero discernía apenas una "vida de moluscos interrumpida por la maravilla inesperada", Antón Arrufat vio el camino recto de una liberación. Pero, de titubeos en afirmaciones rotundas, ¡allá van las contradicciones! Una misma ficción dictada, según Juan José Sebreli, por "esta angustiosa sensación de invasión que el cabecita negra provoca en la clase media", se volvió para Aníbal Ford "un demoledor análisis de la burguesía”, particularmente la burguesía porteña de la época preperonista. Resulta difícil, incongruo elegir entre opiniones tan opuestas cuyo carácter incomprobable refleja mejor las preferencias de cada cual que las motivaciones profundas del autor. Ni las pudo penetrar Luis Harss al interrogarle directamente sobre la identidad de esos "ocupantes desconocidos" responsables de la expulsión. El misterio queda entero. Sin pretender disiparlo, Jean L. Andreu ${ }^{2}$, trató de armonizar este concierto de múltiples disonancias en nombre de una notoria ambigü edad narrativa que, a su entender, otorgaría la mayor diversidad de lecturas. Por más cortazariana que parezca, perspectiva semejante no deja de ser problemática.

Al terminar su relato, el narrador tira a la alcantarilla la llave del enigma. Ahora bien, este ademán, nada equívoco, tiene un sentido preciso, el de cerrar el paso a la interpretación como proceso ideológico exterior al texto. Pero, al mismo tiempo, acaba de consagrar el hermetismo de la obra, cuyos adentros señala como fuente única de significación. A este precio, la libertad del lector.

A primera vista, la historia gira en torno a datos de mera cotidianeidad que le confieren todas las apariencias de una ficción realista. Tiene por marco único un antiguo caserón criollo perfectamente localizable en la Buenos Aires de los años 40 , verdadero islote de paz en medio de los trastornos del siglo. Allí viven los protagonistas dedicándose a las tareas más insignificantes: el tejido de lana, la lectura de los libros. Parece mucho sosiego en una época de guerra y de mutaciones urbanas incompatibles con la conservación de los vestigios. No tardamos en descubrir que ese ambiente íntimo tercamente defendido por los hermanos contra toda agresión exterior, ejerce de por sí mismo, una verdadera tiranía sobre ellos. El aire polvoriento de la capital no basta para justificar la verdadera rabia de limpieza que les acomete por la mañana, ni se aviene la vida humilde que llevan con su desahogo financiero. Así llegamos a sospechar que las que creíamos simples manías de solterones, mal disimulan el deseo secreto de mantener intacto un orden que amenaza ruina. De hecho, el teatro de la acción queda imposible de reconstituir con exactitud. Uno de los méritos de Andreu fue mostrar cómo los rodeos de la descripción logran despistar al lector, paseándole de una pieza a otra, en perpetuo vaivén por un largo pasillo central. Este obligado errar, la fascinación ejercida por aquella "parte más retirada" en la que

2 "Pour une lecture de Casa tomada de J. Cortázar", Cahiers du Monde Hispanique et LusoBrésilien, (Caravelle), $\mathrm{N}^{\circ} 10$, Université de Toulouse, 1968, artículo en que encontrará el lector los datos bibliográficos arriba citados. 
no se penetra nunca, van desprendiendo la ficción de su anclaje realista para iniciar, como bien lo notó Luis Harss, "inquietantes juegos laberínticos".

Tal modificación repercute en el plan del discurso. Dentro del ritmo inmutable de la narración, un repentino futuro acuñado de eternidad, "lo recordaré siempre", suspende una larga serie de imperfectos de costumbre para marcar la irrupción del suceso extraordinario. Patente en la variación temporal, la vacilación se vuelve manifiesta en el uso de las fórmulas modalizantes:

Irene estaba tejiendo en su dormitorio, eran las ocho de la noche y de repente se me ocurrió poner al fuego la pavita del mate. Fui por el pasillo hasta enfrentar la entornada puerta de roble, y daba la vuelta al codo que llevaba a la cocina cuando escuché algo en el comedor o en la biblioteca. El sonido venía impreciso y sordo, como un volcarse de sillas sobre la alfombra o un ahogado susurro de conversación. También lo oí, al mismo tiempo o un segundo después, en el fondo del pasillo que traía desde aquellas piezas hasta la puerta. (p. 152).

Consta observar que la economía de la ambigüedad exige la simetría. Otra observación liminar, "Es casi repetir lo mismo salvo las consecuencias", vuelve a introducir el motivo en términos similares: "(ella tejía) oi ruido". Nuevamente la vacilación raya en alternativa: "tal vez en la cocina o tal vez en el baño", prolongándose el efecto dos frases más adelante:

Nos quedamos escuchando los ruidos, notando claramente que eran de este lado de la puerta de roble, en la cocina y el baño, o en el pasillo mismo... (p. 155) ${ }^{3}$.

Tzvetan Todorovíadvierte que lo fantástico ocupa el tiempo de esta incertidumbre. Dicho enfoque ahorra la referencia, siempre hipotética, a cualquier tipo de intervención natural o sobrenatural, para concentrar el interés sobre la sintaxis del relato. En ambas circunstancias, la percepción del objeto presenta una inmediatez sospechosa. La imagen libre de sus coordinadas se impone al sujeto, sin que éste logre situarla con precisión. Sin embargo, el doble estatuto del agente restablece una supuesta distancia temporal entre el acontecimiento y su recuerdo. Por una parte, el yo del protagonista relaciona lo acaecido con su propia subjetividad, por otra, el narrador anónimo tiende a remediar los fallos de su experiencia sensible con los recursos estilísticos del decir. Dentro del corpus en imperfecto de indicativo, lo expresado en pretérito perfecto absoluto, en virtud de su abstracción misma, recibe una carga de objetividad. Dicho intercambio implica un espacio homogéneo sin perspectiva, una "geografía del descentramiento" en que, estando lo próximo tan presente como lo lejano, resulta fatal el error. Precisamente, - harto lo sugirió la topografía de la casa-el texto configura el más engañoso de los laberintos. Cada frase abre como una puerta sobre la siguiente hasta desembocar en una frase central: "Han tomado la parte del fondo. / - Han tomado esta parte"... Esta frase, situada en el cruce de

3 El subrayado es nuestro.

4 Todorov, Tzvetan, Introducción a la literatura fantástica (Paris: Seuil, 1970). 
ambos aspectos verbales, no tiene salida. Tocamos a la raíz de la ambigüedad: con ser "tomado" por la lectura, el espacio del texto permanece tan cerrado como la casa que lo representa y la palabra de este espacio, al repetirse, pierde sentido o no tiene otro que aprisionar al lector en su irreductible tautología. Pero el pretérito perfecto actual, forma eminentemente perfectiva, invierte los términos del título, volviendo a abrir el texto en sentido contrario, Remite a la paradoja de un discurso, puro reflejo de sí mismo que, partiendo de su imposibilidad de darles cuerpo, tendría por único fin hacer presente la ausencia de las cosas.

El relato, en sus movimientos de carácter laberíntico, plantea pues el enigma de la escritura. "Esta atracción-observa M. Blanchot-que lo divierte hacia un punto infinitamente exterior es el mismo movimiento que lo revierte hacia su propio secreto; hacia su centro, hacia la intimidad a partir de la cual siempre se engendra y se convierte en su propio nacer" 5 . Más hondamente parece determinado por el juego de la diferencia característico de la dinámica del lenguaje. En él, se afrentan dos fuerzas antagónicas: una que aplica el signo a la realidad del mundo, otra que separa al signo de la cosa en la clausura del sistema lingüístico.

Pero la vocación de la literatura es ir más allá de las palabras, hasta denunciar el error que las sustenta. Así, dentro del proceso de devaluación semántica, tiende a veces a compensar la pérdida por el exceso, la proliferación barroca de los accesorios. No se justifican de otro modo los múltiples remiendos operados en la trama del relato. En los momentos de mayor tensión, éste se interrumpe con frecuencia para complacerse en los detalles más anodinos: las pañoletas con naftalina apiladas en el cajón de la cómoda de alcanfor, el polvo en los mármoles de las consolas y entre los rombos de las carpetas de macramé, una primorosa labor de aguja o el mérito de algún sello de Eupen o Malmédy. Tanta insistencia cobra una significación propia: hace las veces de la "figura en el tapiz", la que, en el relato jamesiano, "compone cada línea, elige cada palabra, pone un punto sobre todas las íes, traza todas las comas". Viene a ser el recurso evidente mediante el cual la escritura exalta su valor de ocultamiento. Pero este movimiento que corre y vuelve a correr sin tregua el velo sobre el texto, es el mismo que manifiesta también un extraño poder de revelación. A más de ser arquitecto, Dédalo era también escultor, o sea creador de imágenes, de ficciones en el sentido platónico de la palabra. La ficción presente postula, pues, "una ecuación enigmática entre la figura y el fondo, donde el laberinto no es el fondo sino su metáfora, una realidad segunda que reenvía, como en un decurso espiral, a los trasfondos, el subterráneo, la caverna, el descenso, en suma el revés del secreto". Este juicio de Nicolás Rosa ${ }^{6}$ señala un camino y un fin: el desciframiento del enigma excluye en efecto la línea recta, requiriendo una lectura literal atenta a seguir los meandros del relato. Al principio, éste parece

5 Blanchot, Maurice, Le livre à venir (París: Gallimard, Collection Idées, 1959), p. 134.

6 “Borges o la ficción laberíntica", en Nueva novela latinoamericana (Buenos Aires: Ed. Paidós, 1972), t. II. 
fiel a su vocación primera, la de referir engendramientos:

Nos gustaba la casa porque aparte de la espaciosa y antigua (hoy que las casas antiguas sucumben a la más ventajosa liquidación de sus materiales) guardaba los recuerdos de nuestros bisabuelos, el abuelo paterno, nuestros padres y toda la infancia. (p. 150).

Pero de pronto sale de sus pautas iniciales para deslindar, entre los polos adversos del "tremendum" y del "fascinans", una especie de zona sagrada donde se consume una existencia sin importancia que diríase destinada al holocausto:

Nos moriríamos allí algún día, vagos y esquivos primos se quedarían con

la casa y la echarían al suelo para enriquecerse con el terreno y los ladrillos; o mejor, nosotros mismos la voltearíamos justicieramente antes de que fuera demasiado tarde. (p. 150).

Sólo el tiempo engendra. Todo pasa pues como si, al gastarlo en meros divertimientos, al ubicarse en lo espacial puro en que no tiene parte la genealogía, ese estéril "matrimonio de hermanos" hubiera cometido el sacrilegio mayor connotado por su relación seudo-incestuosa. El teatro de su "locura" se convierte entonces en el espacio que cobija la monstruosidad, espacio teratológico, destinado a celebrar la imposible alianza de los contrarios. Porque ahí la transgresión no tiene lugar: corre el riesgo infinito de incluir la exclusión que viene con el caos. $\mathrm{Y}$ el cuento toma las apariencias de una generación sin parto que no llega a cumplirse, siendo lo no-cumplido su único modo de ser. En su intento siempre fracasado de nombrar lo innominable, sólo da de oir el eco de su propia discordancia, "como un volcarse de sillas (...) o un ahogado susurro de conversación", (p. 152), palabras que no lo son, voces del Tártaro sobre las cuales va cerrando las puertas de lo prohibido.

Estos son los verdaderos límites de un relato que no pasa de ser una figura de su propio secreto. Pero más allá, por fuera de los personajes, se cumple algo que repercute en lo más íntimo suyo, hasta plasmar un desmentido de su existencia personal. Tal es el primer efecto de su retirada:

...nos pareció penoso porque ambos habíamos dejado en la parte tomada muchas cosas que queríamos (...) Pero también tuvimos ventajas, la limpieza de la casa se simplificó (...) Irene estaba contenta le quedaba más tiempo para tejer (...) por no afligir a mi hermana me puse a revisar la colección de estampillas de papá y eso me sirvió para matar el tiempo (...) Estábamos bien, y poco a poco empezábamos a no pensar. Se puede vivir sin pensar. (pp. 153-154).

Tanta resignación ante un destino contrario no deja de extrañar. En realidad la inminencia de la ruptura, siempre exterior al discurso, vuelve a inscribirse en él, bajo el signo de la repulsión. Por eso, apenas si, al evocar su renuncia final, el narrador pone en entredicho un asomo de pena: "Rodeé con mi brazo la cintura de Irene (yo creo que ella estaba llorando) y salimos así a la calle." (p. 155).

El desastre, observa Maurice Blanchot ${ }^{7}$, no tiene alcance. Amenaza siempre

7 "Discours sur la patience" (en marge des livres d'Emmanuel Levinas), en Le Nouveau Commerce (Paris, 1975, Cahier 30-31. 
a y desde ese Otro que separa al hombre de sí mismo, negándole el privilegio de estar en primera persona. Pero la obsesión que lo desidentifica y lo abandona a una pasividad sin iniciativa no deja de marcar en él los rasgos de la trascendencia. La subjetividad misma se vueive capaz de constituir la excepción de lo extraordinario. En el momento de cumplirse el desastre que el relato llama sobre ellos, los protagonistas, enajenados de par en par, caen fuera del ser en las tinieblas exteriores por donde yerran los réprobos. Entonces el enigma de su contra-vivir sólo puede interrogarse mediante las normas de un desdecir, que son las del lenguaje usado para consignar su relación al mundo. Ahora bien, al entrar en el espacio reversible del texto, el lector sustituye al narrador (representado éste en su papel de lector). Ambos comparten un mismo yo anónimo y pasivo hasta el final. Pero al concluir el relato se consuma el divorcio. Mientras el narrador fuera de la casa se vuelve inalcanzable, todo pasa como si el lector, quedado en ella, personificara la amenaza. Se han invertido los papeles, cada uno tomando el sitio del otro, refleja su parte oscura. Forman, pues, en términos cortazarianos, una compleja "figura" de otredad. ${ }^{8}$

Dicho esquema acaba de desvirtuar toda interpretación definitiva. Lo que podía mirarse como una metáfora ilustrando quizá el exilio del hombre en la tierra, viene a significar el exilio mismo en el no-lugar del libro. Exenta de contenido propio, la obra tiende a una apertura total. No es otro el destino de su escritura nómada ${ }^{9}$. Bien lo dice el autor de Rayuela: “...al final, había siempre un hilo tendido más allá, saliéndose del volumen, apuntando a un tal vez, a un a lo mejor, a un quien sabe, que dejaba en suspenso toda visión petrificante..." 10 . "Casa tomada" no infringe la regla: a modo de desenlace, suelta Irene su tejido de lana cuyas hebras se van perdiendo por debajo de la cancel, como para incitarnos, a reanudar sin tregua su hilo de Ariadna: "Palabras, palabras desplazadas y mutiladas, palabras de otros, fue la pobre limosna que le dejaron las horas y los siglos."

Estas líneas de "El inmortal" pueden aplicarse al orden del relato. Señalan el espacio elevado a la significación pura donde incumbe al lector arrojar, a partir del sentido relativo de las cosas, un puente hacia lo absoluto. Hablamos siempre sobre una pérdida de lenguaje, de forma que no decimos nada sin haberlo desdicho previamente. Pero las palabras no son las cosas, y el lenguaje que aquí

8 Dice Cortázar en su entrevista con Luis Harss: “...aparte de nuestros destinos individuales, somos parte de figuras... Siento continuamente la posibilidad de ligazones, de circuitos que se cierran y que nos interrelacionan al margen de toda explicación racional y de toda relación humana..." (En Los nuestros, pp. 227-228).

9 En este sentido Cortázar no renegaría del famoso "Yo, un judío" de Borges, quien, pese a la visible ironía de su fórmula, no deja de reivindicar, hondamente, frente a sus detractores, una certera filiación literaria. Para más datos véase $\mathrm{E}$. Rodríguez Monegal, Borgès par lui-même (Paris: Ed. du Seuil, 1970), que incluye una traducción del texto borgiano publicado en la revista Megáfono $\mathrm{n}^{\circ}$ 12, Buenos Aires, Abril 1934. Sobre la relación judeidad/escritura, el lector consultará con interés "L'imprononçable", en Change, $\mathrm{n}^{\circ}$ 22, Seghers/Laffont, feb. 1975.

${ }^{16}$ En Rayuela (Buenos Aires: Ed. Sudamericana, 15 ${ }^{\text {a }}$ edición, 1973), pp. 602-603. 
se interroga es el que se cuestionaba en Delfos. Necesita para existir las grafías del enigma, afirmando tan sólo el carácter intransitivo de la escritura. Al armar su modelo, el hacedor sólo se hace a sí mismo, abandonando su otro yo a la obra que, en la vacilación incesante de su curso, afrenta la nada de donde viene y a donde vuelve a ser.

Université de Caen

BERNARD FOUQUES 
